${ }^{1}$ Associate Professor, College of Dentistry, Majmaah University, Al Zulfi KSA

${ }^{2}$ Assistant professor, College of Dentistry, Majmaah university, Al Zulfi, KSA. Associate Professor, College of Dentistry, Al-Azhar university, Egypt.
*Corresponding Author: College of Dentistry, Majmaah University, Al Zulfi E mail ID:drtarulatha@gmail.com, t.shyagali@mu.edu.sa Mobile No:0504793029

Received: February 6, 2017 Accepted: August 10, 2017

\section{Prevalence of tobacco usage and its effect on the periodontal health parameters in the mining employees and the general population - A Comparative study}

\author{
Tarulatha R Shyagali ${ }^{1 *}$, Mohamed Helmy Salama², \\ Deepak P Bhayya ${ }^{1}$
}

Objective: Comparison of the prevalence of usage of tobacco products and its effect on the periodontal health parameters of the mining laborers and the general population of Udaipur city, India. Materials and methods: the cross sectional study was performed on the sample of 980 adults including $500 \mathrm{mi}-$ ning employees and 480 subjects from the general population. The presence or absence of the tobacco products usage was noted. The ADA type III examination using the community periodontal probe was done. The data obtained was subjected to chi-square and Cramer' v statistical analysis. Results: 79.40\% of the mining-employees and $61.67 \%$ of the general population used different tobacco products, the difference noted was statistically significant $(p=0.000)$. The most common periodontal condition amongst the mining employees and the general population was the presence of calculus (39\% and $35.63 \%$ respectively) followed by the $4-5 \mathrm{~mm}$ periodontal probing depth (29.20\% and $26.04 \%$ respectively). The difference spotted was significant $(p=0.018)$. There was statistically significant difference between the tobacco users and non- users for the different periodontal conditions $(p=0.000)$. Conclusion: the tobacco product usage was high in mining employees group. There was a positive correlation between the usage of tobacco products and the periodontal health parameters.

Keywords: mining, tobacco use, periodontium, Community Periodontal Index of Treatment Needs 


\section{Introduction}

Mining is one of the ancient occupations in the world. it's viability to cause the disease and injury are well known ${ }^{1}$. There are thousands of people who are working in the mining sector ${ }^{2}$ and the literature is explicit with the ill effects of mining on the general health of the mining employees ${ }^{3,4}$. However, the studies related to oral health condition on the mining employees are very scanty and whatever the few, have explored the areas of oral health conditions like dental caries, the periodontal status, dental wear, cancerous and precancerous lesions ${ }^{5-10}$.

The dust swirling from the mining areas, the populated air and water can be hazardous to human health and it can affect the oral health as well. In addition, the strenuous working condition drives the miners to indulge in adverse habits which can aggravate the ill health condition caused due to the polluted environment. These habits are known to cause the detoriation of oral health. Among the various adverse habits in which the mining employees indulge, oral smokeless tobacco (SLT) and the smoking remain the most prominent. India being a vast country has many states and each state uses its own variant of tobacco product. Bidi and cigarette are widely consumed in India ${ }^{11}$. The smokeless tobacco is consumed either through oral or nasal route. Various SLT used across in India are gutkha, zarda, Mawa and khaini. But, the most popular product among the smokeless tobacco is Khaini' ${ }^{12}$. These are either consumed alone or in various combinations with the other tobacco products ${ }^{13}$. Accordingly, it's been reported that one in four adults and one in ten school students (13-15 years) in India use SLT ${ }^{11}$. The studies have also shown that the oral tobacco products available commercially in India and other Asian countries are highly toxic owing to the presence of more than 4000 chemicals and are known to be highly carcinogenic and mutagenic ${ }^{14,15}$. The prevalence of periodontal disease in India varies from one state to other state, but the $100 \%$ prevalence of periodontal disease is reported in the state of Rajasthan and the Orissa ${ }^{16}$. The association between the tobacco consumption and the periodontal disease is a well-established fact. Both the forms of tobacco are known to cause poor periodontal status, however the smokeless tobacco caused greater attachment loss ${ }^{17}$. About 95\% of the Indian Population suffers from periodontal diseases ${ }^{18}$. According to World Health Organization (WHO) report (1997) in India prominent tobacco products used were Bidis (34\%), Cigarettes (31\%), Chewing tobacco (19\%), Hookah (9\%), Cigars-cheroots (5\%), and Snuff $(2 \%)^{19}$. However, the change in the trend of usage of tobacco product was noticed in the recent survey by cancer patient association of India, their report suggests that the prevalence of the tobacco usage was in the form of cigarettes (20\%), bidis (40\%) and the rest $40 \%$ was consumed in the form of chewable tobacco, pan masala, snuff, gutkha, masheri and tobacco toothpaste ${ }^{20}$. With the noticed trend of tobacco consumption popularity in this part, this study was taken up with the aim to evaluate the periodontal status of the mining employees of the Udaipur city, India and its association with the prevalence of usage of tobacco products. The study also compared the periodontal status of the mining employees with that of the general population. 


\section{Materials and methods}

The cross sectional study was done on 500 mining employees and 480 general populations of age group 18-50 years (Table 1). The comparative group was selected from the population which visited the dental hospital for the routine dental visits. Initially a list of all the mining companies situated in and around the Udaipur city was made. The lottery system was employed to select the different regions for the collection of the data. The post graduate research board of Mohanlal Sukhadia University granted the ethical clearance. The prior permission was obtained from the mining owners for examining the mining employees. The purpose of the study was explained to the subjects and the signed informed consent was obtained before the examination.

A questionnaire was prepared to procure the demographic details of the individuals and to record the presence and absence of the tobacco usage. The subjects who consumed any of the tobacco products less than four times a week, who had a systemic disease and who were on medication for such diseases were excluded from the study. Further, the subjects who were indulged in the usage of tobacco products for more than four times a week and for not less than a year were considered for the study. The questionnaire was filled by the single examiner and the same examiner examined the patient. American Dental Association (ADA) type III examination was carried out with the minimal equipment's which included mouth mirror, community periodontal probe and the chair. The examination of the periodontium was done as per the recommendation of the $\mathrm{WHO}^{21}$. The natural light was used during the examination if the natural light was insufficient than the torch light was used. The cold sterilization procedure was employed to sterilize the instruments.

The collected data was tabulated and the data was subject for the statistical analysis. The chi-square test and the Cramer's v test were performed to evaluate the difference between the mining and non- mining population and between the tobacco users and the non-users.

\section{Results}

Table 1 show the sample distribution of the study population. There were 980 subjects belonging to the age group of 18-50 years. There were 500 mining employees and the control group comprised of 480 subjects from the general population who were not exposed to the mining environment and who belonged to the Udaipur city proper. The main aim of including the control population was to know whether mining environment apart from the tobacco usage has any influence on the periodontal status of the employees.

The demographic data obtained showed that the employees belong to different strata of the working hierarchy, depending upon this the study population was divided into administrative group, maintenance group, transportation group. cutting and polishing groups. Table 2 shows the sample distribution pertaining to the mining employees.

Table 1. Distribution of study population based on groups

\begin{tabular}{llc}
\hline Study Population & $\mathbf{N}^{\circ}$ & $\%$ \\
\hline Marble Mining employees (Study group) & 500 & 51.02 \\
\hline General Population (Comparative group) & 480 & 48.98 \\
\hline Total & 980 & 100 \\
\hline
\end{tabular}


Table 2. Distribution of marble mining labourers based on work units

\begin{tabular}{lcc}
\hline Mining employees (M.E) & No & $\%$ \\
\hline Administrative unit (A) & 43 & 8.60 \\
\hline Maintenance unit (M) & 45 & 9.00 \\
\hline Transportation unit (T) & 140 & 28.00 \\
\hline Cutting unit (C) & 140 & 28.00 \\
\hline Polishing unit (P) & 132 & 26.40 \\
\hline Total & 500 & 100 \\
\hline
\end{tabular}

The table 3 depicts the data in relation to the usage of the tobacco products by the mining employees and the general population. Amongst the mining employees, $79.40 \%$ indulged in tobacco products, whereas, $61.67 \%$ of the general population used the tobacco products. The difference noted was statistically significant.

Table 3. Distribution of study population according to use of tobacco products

\begin{tabular}{|c|c|c|c|c|c|c|c|c|c|}
\hline \multirow{2}{*}{\multicolumn{2}{|c|}{ Tobacco use }} & \multicolumn{5}{|c|}{ Factory employees (F.E) } & \multirow{3}{*}{$\frac{\text { F.E Total }}{397}$} & \multirow{3}{*}{$\begin{array}{l}\text { G.P } \\
296\end{array}$} & \multirow{3}{*}{\begin{tabular}{|l} 
Total \\
693 \\
\end{tabular}} \\
\hline & & \multirow{2}{*}{$\frac{\mathrm{A}}{33}$} & \multirow{2}{*}{$\begin{array}{l}M \\
37\end{array}$} & \multirow{2}{*}{$\frac{\mathbf{T}}{120}$} & \multirow{2}{*}{$\begin{array}{c}\mathrm{C} \\
105\end{array}$} & \multirow{2}{*}{$\begin{array}{c}P \\
102\end{array}$} & & & \\
\hline Hor & No & & & & & & & & \\
\hline Usel & $\%$ & 76.74 & 82.22 & 85.71 & 75.00 & 77.27 & 79.40 & 61.67 & 70.71 \\
\hline \multirow{2}{*}{ Non-user } & No & 10 & 8 & 20 & 35 & 30 & 103 & 184 & 287 \\
\hline & $\%$ & 23.26 & 17.78 & 14.29 & 25.00 & 22.73 & 20.60 & 38.33 & 29.29 \\
\hline \multirow{2}{*}{ Total } & No & 43 & 45 & 140 & 140 & 132 & 500 & 480 & 980 \\
\hline & $\%$ & 100.00 & 100.00 & 100.00 & 100.00 & 100.00 & 100.00 & 100.00 & 100.00 \\
\hline \multicolumn{2}{|c|}{ Chi-square test } & \multicolumn{5}{|c|}{$\begin{array}{c}\chi^{2}=5.839, \mathrm{df}=4, \mathrm{p}=0.211(>0.05) \\
\text { Not Sig. }\end{array}$} & \multicolumn{3}{|c|}{$\begin{array}{c}\chi^{2}=37.188, d f=1 \\
p=0.000(<0.001) \\
\text { Very High Sig. }\end{array}$} \\
\hline \multicolumn{2}{|c|}{ Cramer's V } & \multicolumn{5}{|c|}{0.108} & \multicolumn{3}{|c|}{0.195} \\
\hline
\end{tabular}

The results pertaining to the commonly used tobacco products among the study population is illustrated in table 4. Cigarette, bidi, tobacco leaf, pan, and gutkha were most commonly consumed tobacco products amongst both the study and comparative population. Among mining employees, a majority were using gutkha (38.60\%) followed by tobacco chewing (19.20\%) and bidi smoking (16.0\%). Similar trend was noted for the general population in terms of usage of different tobacco products with gutkha being the most popular product (22.08\%), followed by tobacco chewing (15.42\%) and bidi smoking (13.75\%). Comparison of prevalence of various tobacco habits between mining employees and general population yielded statistically significant differences in the prevalence of pan chewing $(P=0.004)$, and gutkha chewing $(P=0.000)$.

Within mining employees' highest prevalence of gutkha (52.14\%) was seen among of transportation unit workers. While highest prevalence of bidi smoking was seen among polishing unit workers (28.79\%) compared to other units. Whereas prevalence of cigarette smoking and pan chewing was highest among administrative unit. The differences in use of tobacco products among mining employees were statistically significant for all the tobacco products $(P<0.001)$ except for the tobacco leaf. 
Table 4. Distribution of study population according to type of tobacco products

\begin{tabular}{|c|c|c|c|c|c|c|c|c|c|}
\hline \multirow{2}{*}{\multicolumn{2}{|c|}{ Tobacco use }} & \multicolumn{5}{|c|}{ Mining employees } & \multirow{3}{*}{$\begin{array}{c}\text { M.E } \\
\text { Total }\end{array}$} & \multirow{3}{*}{$\begin{array}{c}\text { G.P } \\
30\end{array}$} & \multirow{3}{*}{$\begin{array}{c}\text { Total } \\
52\end{array}$} \\
\hline & & \multirow{2}{*}{$\begin{array}{l}\text { A } \\
08\end{array}$} & \multirow{2}{*}{$\begin{array}{l}M \\
04\end{array}$} & \multirow{2}{*}{$\frac{\mathbf{T}}{10}$} & \multirow{2}{*}{$\begin{array}{c}\mathrm{C} \\
00\end{array}$} & \multirow{2}{*}{$\begin{array}{c}\mathrm{P} \\
00\end{array}$} & & & \\
\hline \multirow{2}{*}{ Cigarette } & No & & & & & & & & \\
\hline & $\%$ & 18.60 & 8.89 & 7.14 & 0.00 & 0.00 & 4.40 & 6.25 & 5.31 \\
\hline \multicolumn{2}{|l|}{ Chi-square test } & \multicolumn{5}{|c|}{$\begin{array}{c}\chi^{2}=37.805, d f=4, p=0.000(<0.001) \\
\text { Very high sig. }\end{array}$} & \multicolumn{3}{|c|}{$\begin{array}{c}\chi^{2}=1.668, \mathrm{df}=1, p=0.197 \\
(>0.05) \text { Not Sig. }\end{array}$} \\
\hline \multicolumn{2}{|l|}{ Cramer's V } & \multicolumn{5}{|c|}{0.275} & \multicolumn{3}{|c|}{0.041} \\
\hline \multirow{2}{*}{ Bidi } & No & 01 & 08 & 08 & 25 & 38 & 80 & 66 & 146 \\
\hline & $\%$ & 2.33 & 17.78 & 5.71 & 17.86 & 28.79 & 16.00 & 13.75 & 14.90 \\
\hline \multicolumn{2}{|l|}{ Chi-square test } & \multicolumn{5}{|c|}{$\begin{array}{c}\chi^{2}=33.529, d f=4, p=0.000(<0.001) \\
\text { Very high sig. }\end{array}$} & \multicolumn{3}{|c|}{$\begin{array}{c}\chi 2=0.978, d f=1, p=0.323 \\
(>0.05) \text { Not Sig. }\end{array}$} \\
\hline \multicolumn{2}{|l|}{ Cramer's V } & \multicolumn{5}{|c|}{0.259} & \multicolumn{3}{|c|}{0.032} \\
\hline \multirow{2}{*}{ Tobacco leaf } & No & 08 & 10 & 28 & 25 & 25 & 96 & 74 & 170 \\
\hline & $\%$ & 18.60 & 22.22 & 20.00 & 17.86 & 18.94 & 19.20 & 15.42 & 17.35 \\
\hline \multicolumn{2}{|l|}{ Chi-square test } & \multicolumn{5}{|c|}{$\begin{array}{c}\chi^{2}=0.501, \mathrm{df}=4, \mathrm{p}=0.973(>0.05) \\
\text { Not Sig. }\end{array}$} & \multicolumn{3}{|c|}{$\begin{array}{c}\chi^{2}=2.445, \mathrm{df}=1, \mathrm{p}=0.118 \\
(>0.05) \text { Not Sig. }\end{array}$} \\
\hline \multicolumn{2}{|l|}{ Cramer's V } & \multicolumn{5}{|c|}{0.032} & \multicolumn{3}{|c|}{0.050} \\
\hline \multirow{2}{*}{ Pan } & No & 04 & 00 & 01 & 00 & 01 & 06 & 20 & 26 \\
\hline & $\%$ & 9.30 & 0.00 & 0.71 & 0.00 & 0.76 & 1.20 & 4.17 & 2.65 \\
\hline \multicolumn{2}{|l|}{ Chi-square test } & & 26.553 & $\begin{array}{l}=4, p= \\
\text { y high s }\end{array}$ & $00(<0$ & & $\begin{aligned} \chi^{2}= & 8.3 \\
& (<0\end{aligned}$ & $\begin{array}{l}\text { df }=1 \\
\text { ) Highl }\end{array}$ & $\begin{array}{l}0.004 \\
\text { ig. }\end{array}$ \\
\hline Cramer's V & & & & 0.230 & & & & 0.092 & \\
\hline cutte & No & 12 & 15 & 73 & 55 & 38 & 193 & 106 & 299 \\
\hline Gutknla & $\%$ & 27.91 & 33.33 & 52.14 & 39.29 & 28.79 & 38.60 & 22.08 & 30.51 \\
\hline Chi-square tes & & & 18.825 & $\begin{array}{l}=4, p= \\
\text { ighly Sic }\end{array}$ & $001(<0$ & & $\begin{aligned} \chi^{2}=31 \\
\quad(<0.0\end{aligned}$ & $\begin{array}{l}\text { df }=1 \\
\text { Very } h\end{array}$ & $\begin{array}{l}=0.000 \\
\text { sig. }\end{array}$ \\
\hline Cramer's V & & & & 0.194 & & & & 0.179 & \\
\hline
\end{tabular}

The data pertaining to the periodontal health parameters is shown in the table 5 . The most common periodontal condition spotted amongst the mining employees and the general population was the presence of calculus (39\% and $35.63 \%$ respectively) followed by the $4-5 \mathrm{~mm}$ periodontal probing depth (29.20\% and $26.04 \%$ respectively). The difference spotted between the two groups was significant.

Table 6 represents the data for the periodontal health status of the mining and the general population in the tobacco and non-tobacco users. The healthy periodontal parameters were appreciated in only $2.02 \%$ of the tobacco user mining population and in $29.13 \%$ of the non-tobacco users. The difference noted was statistically significant. There was statistically significant difference between the tobacco users and non- users for the different periodontal conditions in both the mining employees group $(p<0.001)$ and the general population $(p<0.001)$.

\section{Discussion}

The indulgence in tobacco has multitude of oral health problems which can range from developing oral cancerous and precancerous lesions to the detoriation of periodontal health. It can also cause delay in oral wound healing, can contribute significantly for the halitosis, can cause staining of teeth, can trigger negative immune 
Table 5. Distribution of study population according to community periodontal index (CPI) scores.

\begin{tabular}{|c|c|c|c|c|c|c|c|c|c|}
\hline \multirow{2}{*}{ CPI } & & \multicolumn{5}{|c|}{ Factory employees } & \multirow{2}{*}{$\begin{array}{l}\text { F.E } \\
\text { Total }\end{array}$} & \multirow{2}{*}{ G.P. } & \multirow{2}{*}{ Total } \\
\hline & & $A$ & $M$ & $T$ & $\mathrm{C}$ & $P$ & & & \\
\hline \multirow{2}{*}{ Healthy } & No & 10 & 8 & 5 & 8 & 7 & 38 & 50 & 88 \\
\hline & $\%$ & 23.26 & 17.78 & 3.57 & 5.71 & 5.30 & 7.60 & 10.42 & 8.98 \\
\hline \multirow{2}{*}{ Bleeding } & No & 5 & 10 & 20 & 26 & 28 & 89 & 116 & 205 \\
\hline & $\%$ & 11.63 & 22.22 & 14.29 & 18.57 & 21.21 & 17.80 & 24.17 & 20.92 \\
\hline \multirow{2}{*}{ Calculus } & No & 15 & 16 & 60 & 44 & 60 & 195 & 171 & 366 \\
\hline & $\%$ & 34.88 & 35.56 & 42.86 & 31.43 & 45.45 & 39.00 & 35.63 & 37.35 \\
\hline \multirow{2}{*}{$4-5 m m$} & No & 11 & 8 & 46 & 51 & 30 & 146 & 125 & 271 \\
\hline & $\%$ & 25.58 & 17.78 & 32.86 & 36.43 & 22.73 & 29.20 & 26.04 & 27.65 \\
\hline \multirow{2}{*}{$6 \mathrm{~mm}$ or more } & No & 2 & 3 & 9 & 11 & 7 & 32 & 18 & 50 \\
\hline & $\%$ & 4.65 & 6.67 & 6.43 & 7.86 & 5.30 & 6.40 & 3.75 & 5.10 \\
\hline \multirow{2}{*}{ Total } & No & 43 & 45 & 140 & 140 & 132 & 500 & 480 & 980 \\
\hline & $\%$ & 100 & 100 & 100 & 100 & 100 & 100 & 100 & 100 \\
\hline \multicolumn{2}{|l|}{ Chi-square test } & \multicolumn{5}{|c|}{$\begin{array}{c}\chi^{2}=40.351, \mathrm{df}=16, \mathrm{p}=0.001(<0.01) \\
\text { Highly sig. }\end{array}$} & \multicolumn{3}{|c|}{$\begin{array}{c}\chi^{2}=11.910, \mathrm{df}=4 \\
p=0.018(<0.05) \\
\text { Sig. }\end{array}$} \\
\hline Cramer's V & & \multicolumn{5}{|c|}{0.142} & \multicolumn{3}{|c|}{0.110} \\
\hline
\end{tabular}

*A - Administrative unit; M-Maintenance unit; T-Transportation unit; C-Cutting unit; P-Polishing unit; F.E -Factory employees; G.P-General Population

Table 6. Distribution of CPI scores among user and non-user of tobacco products among study population

\begin{tabular}{|c|c|c|c|c|c|}
\hline \multirow{2}{*}{\multicolumn{2}{|c|}{ CPI scores }} & \multicolumn{2}{|c|}{ Factory employees } & \multicolumn{2}{|c|}{ General Population } \\
\hline & & Non- users & Users & Non-users & Users \\
\hline \multirow{2}{*}{ Healthy } & No & 30 & 8 & 44 & 6 \\
\hline & $\%$ & 29.13 & 2.02 & 23.91 & 2.03 \\
\hline \multirow{2}{*}{ Bleeding } & No & 15 & 74 & 44 & 72 \\
\hline & $\%$ & 14.56 & 18.64 & 23.91 & 24.32 \\
\hline \multirow{2}{*}{ Calculus } & No & 40 & 155 & 78 & 93 \\
\hline & $\%$ & 38.83 & 39.04 & 42.39 & 31.42 \\
\hline \multirow{2}{*}{$4-5 m m$} & No & 15 & 131 & 12 & 113 \\
\hline & $\%$ & 14.56 & 33.00 & 6.52 & 38.18 \\
\hline \multirow{2}{*}{$6 \mathrm{~mm}$ or more } & No & 3 & 29 & 6 & 12 \\
\hline & $\%$ & 2.91 & 7.30 & 3.26 & 4.05 \\
\hline \multirow{2}{*}{ Total } & No & 103 & 397 & 184 & 296 \\
\hline & $\%$ & 100 & 100 & 100 & 100 \\
\hline \multicolumn{2}{|l|}{ Chi-square test } & \multicolumn{2}{|c|}{$\begin{array}{c}\chi^{2}=91.840, \mathrm{df}=4 \\
\mathrm{p}=0.000(<0.001) \\
\text { Very high sig. }\end{array}$} & \multicolumn{2}{|c|}{$\begin{array}{c}\chi^{2}=99.866, \mathrm{df}=4 \\
\mathrm{p}=0.000(<0.001) \\
\text { Very high sig. }\end{array}$} \\
\hline Cramer's V & & \multicolumn{2}{|c|}{0.429} & \multicolumn{2}{|c|}{0.456} \\
\hline
\end{tabular}

response, can alter the $\mathrm{pH}$ of the oral cavity ${ }^{22,23}$. The current article explored the association of usage of tobacco products and the periodontal health parameters in the mining employees and the general population.

Around $79.40 \%$ and $61.67 \%$ of the mining employees and the general population indulged in one or the other form of tobacco usage. The difference found was very highly significant indicating that the tobacco usage was more common in the mining employees and the reason for this might be the tobacco can act as a relaxer after the strenuous 
laboring involved in the mining occupation. The earlier reports also highlight this finding that the tobacco usage is most commonly seen amongst the middle and low income countries and that too in population belonging to low socioeconomic strata and low literacy rate ${ }^{24,25}$. There was no difference amongst the different categories of the mining employees for the usage of tobacco products. However, the transportation unit and the maintenance unit used tobacco more than the other units. The type of tobacco which was used by most of the mining employees were gutkha and the tobacco leaves, which were both the chewable forms of the tobacco. The oral hygiene habit showed that all the mining employees had the habit of brushing their teeth once daily.

Presence of the calculus (39\%, 35.63\%) was the most prevalent of all the periodontal conditions in the mining employees and the general population respectively, this was followed by the presence of periodontal pocket of $4-5 \mathrm{~mm}$ depth which was seen in $29.20 \%$ of mining employees and $26.04 \%$ in the general population. The periodontal conditions were more in tobacco using group than the rest and the same finding is proved in the earlier studies as well ${ }^{26-33}$.

The healthy periodontium was seen more in case of general population (10.42\%) than the mining employees (7.60\%). The difference noted between the mining employees and the general population was statistically significant $(p<0.05)$. The periodontal health parameters noticed for the non-mining population in the current study are in agreement with the results of the previous studies conducted on the general population ${ }^{18}$.

The difference in the periodontal condition for the different units of mining employees was statistically highly significant $(p<0.01)$ with greater incidence of calculus in polishing unit employees. Higher incidence of pocket depth of $4-5 \mathrm{~mm}$ was seen in the cutting unit employees. This difference noted amongst the different group of mining employees is probably associated with the type of tobacco product they consumed. For example, the polishing unit and the cutting unit employees consumed bidi (a type of tobacco used for smoking) more than the other unit employees. Apart from this the duration and the frequency of indulgence in the habit is directly proportional to the adversity of the periodontal condition. The mining employees and the general population both indulged in the usage of tobacco products not less than four times a day. The same fact has been emphasized in the earlier studies as well28,31.

Around $29.13 \%$ of the tobacco non-user group of the mining employees had healthy periodontium. However, the users both in the mining population and the general population had around $2 \%$ healthy periodontium. Most common periodontal conditions seen in the tobacco users in the mining population was presence of calculus (39.04\%) and the pocket depth of 4-5 mm (33\%). Similar findings have been reported in the literature 33,34 .

However, in the non-tobacco users the presence of the calculus (38.83\%) was most commonly spotted. The difference noted for the periodontal parameters in both the mining employees and the general population for the tobacco users and non-users was statistically very highly significant $(p<0.001)$. This again proves the significant contribution of tobacco usage in increasing the oral health burden globally. The results of the current study are in agreement with previous study of the similar nature ${ }^{29,35-37}$. The scope of the current manuscript was to find the prevalence rate of periodontal 
disease status in tobacco usage sample, nevertheless the study carries the further scope to explore the relationship between the periodontal disease and the frequency of usage of tobacco products.

\section{Conclusion}

The periodontal status of the current group of mining employees is very poor in comparison to general population and its association with the usage of tobacco product is well proven. This emphasizes the need to conduct regular dental health education and checkup camps to improve the awareness of the effects of the tobacco product usage.

\section{References}

1. Donoghue AM. Occupational health hazards in mining: an overview. Occup Med (Lond). 2004 Aug;54(5):283-9.

2. Semple S, Green DA, McAlpine G, Cowie H, Seaton A. Exposure to particulate matter on an Indian stone-crushing site. Occup Environ Med. 2008 May;65(5):300-5.

3. Oliveira A, Cacodcar J, Motghare DD. Morbidity among iron ore mine workers in Goa. Indian J Public Health. 2014 Jan-Mar;58(1):57-60. doi: 10.4103/0019-557X.128171.

4. Nandi SS, Dhatrak SV, Chaterjee DM, Dhumne UM. Health Survey in Gypsum Mines in India. Indian J Community Med. 2009 Oct;34(4):343-5. doi: 10.4103/0970-0218.58396.

5. Petersen PE, Gormsen C. Oral conditions among German battery factory workers. Community Dent Oral Epidemiol. 1991 Apr;19(2):104-6.

6. Petersen PE, Henmer P. Oral conditions among workers in the Danish granite factory industry. Scand J Work Environ Health. 1988 Oct;14(5):328-31.

7. Petersen PE, Tanase M. Oral health status of an industrial population in Romania. Int Dent J. 1997 Aug;47(4):194-8.

8. Sanadhya S, Nagarajappa R, Sharda AJ, Asawa K, Tak M, Batra M, et al. The oral health status and the treatment needs of salt workers at sambhar lake, Jaipur, India. J Clin Diagn Res. 2013 Aug;7(8):1782-6. doi: 10.7860/JCDR/2013/5887.3275.

9. Sharma A, Thomas S, Dagli RJ, Solanki J, Arora G, Singh A. Oral health status of cement factory workers, Sirohi, Rajasthan, India. J Health Res Rev. 2014;1(1):15-9.

10. Sood M, Blaggana A, Blaggana V, Sharma V. Occupational Dental Wear among Ceramic Factory Workers - An Observational Study. J All India Dent Assoc. 2011;5(4):472-3.

11. Gupta PC, Arora M, Sinha D, Asma S, Parascondola M. Smokeless Tobacco and Public Health in India. Government of India, Ministry of Health and Family Welfare; 2012. p. 1-14.

12. Singh A, Ladusingh L. Prevalence and determinants of tobacco use in India: evidence from recent global adult tobacco survey data. PLoS One. 2014 Dec 4;9(12):e114073. doi: 10.1371/journal.pone.0114073.

13. Mohan P, Lando HA. Oral tobacco and mortality in India. Indian J Clin Med. 2016;7:5-12.

14. Nair U, Bartsch H, Nair J. Alert for an epidemic of oral cancer due to use of the betel quid substitutes gutkha and pan masala: A review of agents and causative mechanisms.

Mutagenesis. 2004 Jul;19(4):251-62. 
15. Bhisey R A. Chemistry and toxicology of smokeless tobacco. Indian J Cancer. 2012 Oct-Dec;49(4):364-72. doi: 10.4103/0019-509X.107735.

16. Shah N, Pandey RM, Duggal R, Mathur VP, Rajan K. Oral Health in India: a report of the multi centric study. Directorate General of Health Services, Ministry of Health and Family Welfare, Government of India and World Health Organisation Collaborative Program; 2007 Dec.

17. Katuri KK, Alluri JK, Chintagunta C, Tadiboina N, Borugadda R, Loya M et al. Assessment of Periodontal Health Status in Smokers and Smokeless Tobacco Users: A Cross-Sectional Study. J Clin Diagn Res. 2016 Oct;10(10):ZC143-ZC146.

18. Chandra A, Yadav OP, Narula S, Dutta A. Epidemiology of periodontal diseases in Indian population since last decade. J Int Soc Prev Community Dent. 2016 Mar-Apr;6(2):91-6. doi: 10.4103/2231-0762.178741.

19. WHO. Tobacco or health: A global status report. WHO publication: Geneva: WHO; 1997

20. Chaly PE. Tobacco control in India. Indian J Dent Res. 2007 Jan-Mar;18(1):2-5.

21. Oral Health Survey-Basic Methods. $5^{\text {th }}$ ed. Geneva, Switzerland: WHO; 2013.

22. Mubeen K, Chandrashekhar H, Kavitha M, Nagarathna S. Effect of Tobacco on oral-Health an Overview. J Evol Med Dental Sci. 2013 May;2(20):3523-34.

23. Malhotra R, Kapoor A, Grover V, Kaushal S. Nicotine and periodontal tissues. J Indian Soc Periodontol. 2010 Jan;14(1):72-9. doi: 10.4103/0972-124X.65442.

24. Johnson, NW, Bain C. Tobacco and oral disease. EU-Working Group on Tobacco and Oral Health. Br Dent J. 2000 Aug;189(4):200-6.

25. Mackay J, Eriksen M. The Tobacco Atlas. Geneva: World Health Organization; 2002. p. 1-128.

26. Grossi SG, Zambon JJ, Ho AW, Koch G, Dunford RG, Machtei EE, et al. Assessment of risk for periodontal disease. I. Risk indicators for attachment loss. J Periodontol. 1994 Mar;65(3):260-7.

27. Grossi SG, Genco RJ, Machtei EE, Ho AW, Koch G, Dunford R, et al. Assessment of risk for periodontal disease. II. Risk indicators for alveolar bone loss. J Periodontol. 1995 Jan;66(1):23-9.

28. Martinez-Canut P, Lorca A, Magán R. Smoking and periodontal disease severity. J Clin Periodontol. 1995 Oct;22(10):743-9.

29. Haber J, Kent RL. Cigarette smoking in periodontal practice. J Periodontol. 1992 Feb;63(2):100-6.

30. Alpagot T, Wolff LF, Smith QT, Tran SD. Risk indicators for periodontal disease in a racially diverse population. J Clin Periodontol. 1996 Nov;23(11):982-8.

31. Wouters FR, Salonen LW, Frithiof L, Helldén LB. Significance of some variables on interproximal alveolar bone height based on cross-sectional epidemiological data. J Clin Periodontol. 1993 Mar;20(3):199-206.

32. Machuca G, Rosales I, Lacalle JR, Machuca C, Bullon P. Effect of cigarette smoking on periodontal status of healthy young adults. J Periodontol. 2000 Jan;71(1):73-8.

33. Bergstrom J. Tobacco smoking and supragingival dental calculus. J Clin Periodontol. 1999 Aug;26(8):541-7.

34. Muller HP, Stadermann S, Heinecke A. Longitudinal association between plaque and gingival bleeding in smokers and non-smokers. J Clin Periodontol. 2002 Apr;29(4):287-94.

35. Bergstrom J. Cigarette smoking as risk factor in chronic periodontal disease. Community Dent Oral Epidemiol. 1989 Oct;17(5):245-7.

36. Amarasena N, Ekanayaka AN, Herath L, Miyazaki H. Tobacco use and oral hygiene as risk indicators for periodontitis. Community Dent Oral Epidemiol. 2002 Apr;30(2):115-23.

37. Tomar SL, Asma S. Smoking-attributable periodontitis in the United States: findings from NHANES III. National Health and Nutrition Examination Survey. J Periodontol. 2000 May;71(5):743-51. 